Check for updates

Cite this: RSC Adv., 2018, 8, 4779

\title{
Vapor deposition of polyionic nanocoatings for reduction of microglia adhesion $\uparrow$
}

\begin{abstract}
Bin Zhi, Qing Song and Yu Mao (D)*
Polyionics have great potential in improving the performance of neural probes by regulating microglial response. With the shrinkage of microelectrode size and increase in device complexity, challenges arise during liquid-based synthesis of polyionic compounds on neural probes. Nanocoatings of polyionics, with highly crosslinked bulk structure and abundant ionic functional groups on the surface, were synthesized using a process combining chemical vapor deposition and free radical polymerization. Both conformal surface engineering of neural microelectrodes and facile tailoring of surface ionic composition was achieved using this single-step vapor-based method. Adhesion of microglia was reduced on all the polyionic modified surfaces after a seven-day in vitro test, and polyionics with mixed charges presented much lower microglial adhesion than surfaces with single charges. Laminin adsorption on polyionics with mixed charges was significantly reduced due to the surface electrical neutrality and the enhanced wettability. These findings provide valuable information towards the development of neural probes with enhanced biocompatibility and signal stability.
\end{abstract}

Received 23rd November 2017 Accepted 1st January 2018

DOI: $10.1039 / c 7 r a 12728 f$

rsc.li/rsc-advances microglia attachment and suppress its activation. ${ }^{\mathbf{1 9 2 0}}$ The interleukin-1 receptor antagonist was reported to reduce $50 \%$ microglia attachment in rats after one month, ${ }^{21}$ and dexamethasone has been used for localized release to suppress microglial response on implanted neural probes in vivo. ${ }^{\mathbf{2 6}}$

Tailoring the surface chemistry of implants offers another route to improve the biocompatibility with neural tissue. ${ }^{27,28}$ Hydrophilic surfaces have been known to decrease non-specific protein adsorption, ${ }^{29-31}$ which provides the potential for suppressing microglial response. The hydrogel of poly $(N$-isopropylacrylamide) was reported to significantly reduce macrophage adhesion and expression of pro-inflammatory cytokines. ${ }^{32}$ Spin coated cellulose hydrogel was reported to lower the 24 h-microglia adhesion by $80 \%$ in vitro. ${ }^{11}$ In vivo studies showed that photo-polymerized poly(ethylene glycol)based hydrogel exhibits lower microglia adhesion after 56 days of implantation, ${ }^{33}$ and poly(vinyl alcohol)/poly(acrylic acid) hydrogel reduced microglia adhesion by $30 \%$ after six weeks of implantation. ${ }^{\mathbf{3 4}}$

An important factor to consider in hydrogel surface engineering of microelectrodes is the effect of modification on neural signal recording. For non-charged hydrogels, such as alginate, significant signal loss was observed at $5 \mu \mathrm{m}$-thickness due to spatial displacement of neurons. ${ }^{35}$ On the other hand, mixed charged nitrocellulose-based hydrogel of micron thickness has been studied, which showed no increase in electrode impedance. ${ }^{19}$ At sub-micron thickness, charged hydrogels were reported to reduce electrode impedance due to the presence of an ionic conductive layer in contact with electrodes. ${ }^{36}$ Lowering electrode impedance is particularly important for ultra-small
Department of Biosystems Engineering, Oklahoma State University, Stillwater, Oklahoma 74078, USA. E-mail: yu.mao@okstate.edu

$\dagger$ Electronic supplementary information (ESI) available: Dynamics of $24 \mathrm{~h}$ BSA adsorption on polyionics with single and mixed charges studied by monitoring the frequency change using QCM. See DOI: 10.1039/c7ra12728f 
multi-electrode arrays ${ }^{1,37}$ as smaller electrodes can further reduce neural tissue damage after implantation ${ }^{38,39}$ and improve biocompatibility. ${ }^{40}$ However, with reduced electrode size and increase in device complexity, challenges arise in hydrogel surface engineering using traditional processing methods, such as spin coating, ${ }^{11,19}$ photo polymerization, ${ }^{33}$ and aqueous crosslinking. ${ }^{34}$

In this study, we investigated the synthesis of polyionic nanocoatings and the surface engineering of microelectrodes using an initiated chemical vapor deposition (iCVD) method, which combines free radical polymerization and chemical vapor deposition for in situ deposition of chain-growth polymers. ${ }^{41-44}$ Positively, negatively, and mixed-charged nanocoatings were synthesized and characterized. The in vitro cell culture tests showed that the mixed-charged polyionics presented minimum microglial adhesion among all the polyionics. Surface protein adsorption of bovine serum albumin (BSA) and laminin were also quantified. BSA was chosen as a model protein for the surface adsorption study. Laminin is a major glycoprotein of basement membrane that plays an important role in the adhesion of activated microglia. ${ }^{45,46}$ The vapor-deposited polyionics formed conformal nanocoatings around microelectrodes, indicating promising applications in surface engineering of ultra-small neural electrodes.

\section{Experimental}

\section{Materials}

Methacrylic acid (MAA, 99\%), 2-dimethylamino ethyl methacrylate (DMAEMA, 98\%), ethylene glycol diacrylate (EGDA, 90\%), and tert-butyl peroxide (TBP, 98\%) were purchased from SigmaAldrich and used without further purification. Silicon wafers $(\mathrm{P} /$ boron $\langle 100\rangle)$ were purchased from WRS Materials. Aclar film was purchased from Ted Pella. Monopolar microelectrodes were generously provided by FHC. BSA was purchased from Sigma-Aldrich. Mouse laminin (ultrapure) was purchased from BD. PBS (pH 7.4) was purchased from Fisher Scientific. Dodecyl sulfate sodium (SDS, 99\%) was purchased from Acros. Micro BCA Protein Assay Kit was purchased from Pierce. Mouse C8-B4 microglia (CRL-2540) and Dulbecco's Modified Eagle's Medium (DMEM) were purchased from ATCC. Penicillin-streptomycin, Fetal Bovine Serum (FBS), and $0.25 \%$ trypsin-EDTA were purchased from Life Technologies.

\section{Nanocoating synthesis}

Hybrid nanocoatings of poly(methacrylic acid-co-ethylene glycol diacrylate) (PME), poly(2-dimethylamino ethyl methacrylate-coethylene glycol diacrylate) (PDE), and poly(2-dimethylamino ethyl methacrylate- $c o$-methacrylic acid-co-ethylene glycol diacrylate) (PDME) were synthesized using the iCVD method described in previous studies. ${ }^{41-44}$ The initiator of TBP was vaporized at room temperature and fed into the reactor using a mass flow controller (MKS, model 1479A). The monomers of DMAEMA and MAA were both vaporized at $50{ }^{\circ} \mathrm{C}$ and injected into the reactor using mass flow controllers (MKS, model 1153 and 1150). The crosslinker of EGDA was vaporized at $55^{\circ} \mathrm{C}$ and injected through a needle valve (Swagelok). The flow rates of DMAEMA, MAA, and EGDA were varied (Table 1) at each stage of deposition to form a hybrid structure, while the TBP flow rate was maintained constant at $0.24 \mathrm{sccm}$. Inside the reactor, vapor monomers were heated up by a parallel array of nichrome filament (Ni80/Cr20, Goodfellow) that was resistively heated to $220{ }^{\circ} \mathrm{C}$. Substrates for coating were placed on a water-cooled stage at $40{ }^{\circ} \mathrm{C}$ during deposition. The temperatures were monitored by thermocouples (Omega, Type K) that were directly attached to the filament and the stage. Pressure in the vacuum chamber was maintained at 300 mTorr using a butterfly valve (MKS, model 253B). The increase in thickness of the nanocoatings was measured in situ using an interferometry system with a $633 \mathrm{~nm} \mathrm{He-Ne} \mathrm{laser} \mathrm{(JDS} \mathrm{Uniphase).} \mathrm{The} \mathrm{collected} \mathrm{laser}$ signal was recorded as cycling waves, and the thickness corresponding to each cycle, as measured via interferometry, was calibrated using variable-angle spectroscopic ellipsometry (VASE). The nanocoated samples were soaked in deionized water for $2 \mathrm{~h}$, followed by rinsing three times to remove any uncrosslinked polymers.

\section{Characterizations}

Fourier transform infrared (FTIR) spectra were collected by a Nicolet 6700 FTIR spectrometer using a DTGS detector under the transmission mode at $4 \mathrm{~cm}^{-1}$ resolution. Surface wettability was measured using a goniometer (Ramé-Hart, model 250-F1). Static contact angle was accessed by the standard sessile drop method using a $5 \mu \mathrm{L}$ droplet of deionized water. Advancing and receding contact angles were accessed using the tilting plate method with a tilting speed of $1^{\circ} \mathrm{s}^{-1}$. Each measurement was repeated three times at different spots on all samples. The mobility factor (MF) of the surface was calculated from the advanced and receding contact angles $\left(\theta_{\mathrm{a}}\right.$ and $\theta_{\mathrm{r}}$, respectively) using the following equation: $\mathrm{MF}=\left(\theta_{\mathrm{a}}-\theta_{\mathrm{r}}\right) / \theta_{\mathrm{a}}{ }^{47}{ }^{4} \mathrm{X}$-ray photoelectron spectroscopy (XPS) measurements were performed using a $300 \mathrm{~W} \mathrm{Mg} \mathrm{K} \alpha$ source and PHI double-pass cylindrical mirror analyzer with a pass energy of $50 \mathrm{eV}$. The morphology of the neural microelectrodes before and after coating was analyzed using a FEI Quanta 600 field-emission gun scanning electron microscope (SEM) operated at an acceleration voltage of $25 \mathrm{kV}$. Quartz crystal microbalance (QCM) measurements were performed using Q-Sense E1 equipped with QSX 301 sensors. The resonance frequency $f$ was measured at the fundamental resonance frequency of $5 \mathrm{MHz}$ and the third

Table 1 Flow rate and thickness control during iCVD coating synthesis

\begin{tabular}{|c|c|c|c|c|c|}
\hline & \multirow[b]{2}{*}{ Stage } & \multicolumn{3}{|c|}{ Flow rate/sccm } & \multirow[b]{2}{*}{ Thickness/nm } \\
\hline & & MAA & DMAEMA & EGDA & \\
\hline \multirow[t]{2}{*}{ PME } & I & 0.56 & 0 & 0.26 & 200 \\
\hline & II & 0.56 & 0 & 0 & 50 \\
\hline \multirow[t]{2}{*}{ PDE } & I & 0 & 0.55 & 0.28 & 200 \\
\hline & II & 0 & 0.55 & 0 & 50 \\
\hline \multirow[t]{2}{*}{ PDME } & I & 0.36 & 0.03 & 0.40 & 200 \\
\hline & II & 0.36 & 0.03 & 0 & 50 \\
\hline
\end{tabular}


overtone. Experiments were conducted in a continuous flow cell using a peristaltic pump.

\section{Protein adsorption assay}

Measurement of BSA and laminin surface adsorption was conducted on coated 96-well plates using the Micro BCA Protein Assay Kit. An aliquot of $100 \mu \mathrm{L}$ of protein solution at $100 \mu \mathrm{g}$ $\mathrm{mL}^{-1}$ was added to each well and incubated at $37{ }^{\circ} \mathrm{C}$ for $1 \mathrm{~h}$, $24 \mathrm{~h}$, or $168 \mathrm{~h} .{ }^{48}$ After incubation, each well was rinsed by PBS for three times, followed by incubation with $100 \mu \mathrm{L}$ SDS (3\%) at $37^{\circ} \mathrm{C}$ for $1 \mathrm{~h}$. Subsequently, an aliquot of $50 \mu \mathrm{L}$ was mixed with $50 \mu \mathrm{L}$ BCA reagent at $37{ }^{\circ} \mathrm{C}$ for $2 \mathrm{~h}$. Absorption at $562 \mathrm{~nm}$ was measured using an Infinite M200 multimode microplate reader (Tecan). Protein concentration was determined using the standard curve of BSA as reference.

\section{Microglia adhesion assay}

C8-B4 microglia was cultured in DMEM supplemented with $10 \% \mathrm{FBS}, 50 \mathrm{U} \mathrm{mL}^{-1}$ penicillin, and $50 \mu \mathrm{g} \mathrm{mL}^{-1}$ streptomycin. Due to the uneven microglia distribution observed in the wells of microplates, Aclar films were used for the adhesion assay. Microglia was seeded onto Aclar films placed in a 6-well plate at a density of $1 \times 10^{5}$ cells per $\mathrm{mL}$ and $5 \times 10^{4}$ cells per $\mathrm{mL}$ for the $24 \mathrm{~h}$ and $168 \mathrm{~h}$ adhesion tests, respectively. At the end of each cell test period, Aclar films were retrieved and rinsed with sterile PBS three times to remove any non-adherent cells. Microglia adhesion was observed under a DMI3000M microscope (Leica) and the digital images were recorded for five randomly selected, $1 \times 1 \mathrm{~mm}^{2}$ fields of each sample. Average microglia adhesion density (cells per $\mathrm{mm}^{2}$ ) was calculated by quantifying the number of adherent cells through the image analysis of Leica Application Suite. The microglia adhesion experiments were run in triplicate.

\section{Statistics}

Statistical analysis was performed using SAS software (SAS Institute Inc., Cary, N.C.). Statistical comparisons were made by one-way analysis of variance (Anova). The Student's $t$-test was used for post hoc evaluation of differences among groups. In all statistical evaluations, $p<0.05$ was considered as statistically significant.

\section{Results and discussion}

\section{Hybrid polyionic nanocoatings}

Polyionics of PME, PDE and PDME were synthesized using the one-pot, two-stage iCVD process illustrated in Fig. 1. Initially, vaporized monomers MAA and DMAEMA and the crosslinker EGDA were metered into the reaction chamber along with the initiator TBP. The process involves thermal decomposition of TBP over heated filaments to create free radicals in the vapor phase and subsequent free radical co-polymerization of the monomer and the crosslinker, forming crosslinked polyionics directly on the solid substrate. The advantage is that the substrate remained at relatively low temperatures $\left(\sim 40{ }^{\circ} \mathrm{C}\right)$ and the method does not involve the use of any solvents since the entire process takes place in the vapor and solid phase. At the second stage, the flow of crosslinker was switched off, while the flow of monomer vapors was continued to allow grafting polymerization of polyionics from the unterminated radical sites of the crosslinked layer, resulting in surface enrichment with polyionics, which will be discussed later. Details of flow rate and thickness control at each stage are listed in Table 1. The resultant coating has a hybrid structure comprising a highly crosslinked bulk and a surface layer enriched with polyionics.

The overall composition of the hybrid polyionic nanocoatings was characterized by FT-IR (Fig. 2). Homopolymers of poly(2-dimethylamino ethyl methacrylate) (PDMAEMA), poly(methacrylic acid) (PMAA), and poly(ethylene glycol diacrylate) (PEGDA) were also synthesized via iCVD for comparison. The absorption peak at $1702 \mathrm{~cm}^{-1}$ in the spectra of PMAA, PME, and PDME was assigned to $\mathrm{C}=\mathrm{O}$ stretching of carboxyl in the MAA moiety, ${ }^{49}$ while the absorption peaks at 2772 and $2821 \mathrm{~cm}^{-1}$ in the spectra of PDMAEMA and PDE were assigned to $\mathrm{C}-\mathrm{H}$ stretching of tertiary amine in the DMAEMA moiety. ${ }^{50}$ Interestingly, the $\mathrm{C}-\mathrm{H}$ stretching bands at 2772 and $2821 \mathrm{~cm}^{-1}$ are not observed in the FT-IR spectrum of PDME, while an absorption peak is observed at $1565 \mathrm{~cm}^{-1}$. The new absorption peak was attributed to the close interaction between amine and carboxyl groups, ${ }^{\mathbf{5 1}}$ which could possibly result in changes in the $\mathrm{C}-\mathrm{H}$ stretching modes. The FT-IR of poly(methacrylic acid-co-2-dimethylamino ethyl methacrylate) (not shown) exhibited a similar absence of $\mathrm{C}-\mathrm{H}$ stretching at 2772 and $2821 \mathrm{~cm}^{-1}$ and a slightly higher absorption at $1565 \mathrm{~cm}^{-1}$. The absorption at $1728 \mathrm{~cm}^{-1}$ and $1735 \mathrm{~cm}^{-1}$ shown in the spectra of PDME, PDE, and PME are assigned to $\mathrm{C}=\mathrm{O}$ stretching in DMAEMA and EGDA, respectively. The assignment of FT-IR absorption bands is summarized in Table S1. $\dagger$ Overall, the above results indicated that DMAEMA, MAA, and EGDA were incorporated into the nanocoatings. The enrichment of DMAEMA and MAA moieties at the top surface of hybrid nanocoatings was verified by XPS survey scans. For example, the nitrogen to carbon (N/C) atomic ratio of hybrid $\mathrm{PDE}$ is $7 \%$ higher than the $\mathrm{N} / \mathrm{C}$ ratio of homogeneous PDE, indicating higher concentration of DMAEMA at the top surface of hybrid PDE compared with the non-grafted PDE.

Neural microelectrodes were engineered using the hybrid vapor deposition process. Fig. 3 shows the microelectrodes after the deposition of $250 \mathrm{~nm}$-PDME nanocoating. Nanocoatings with thickness below $50 \mathrm{~nm}$ can be deposited, ${ }^{\mathbf{4 1 , 4 3}}$ but this deposition condition was chosen to maintain the same composition as that of PDME nanocoating in characterization studies. Due to the vapor-based process, the nanocoating was conformal and uniform throughout the entire surface of each individual microelectrode. The conformal feature of iCVD nanocoatings has been clearly demonstrated in the surface engineering of nanostructures we previously reported. ${ }^{\mathbf{4 1 , 4 3}}$ No change in the morphology of microelectrode was observed because of the huge dimension discrepancy between the 100 $\mu \mathrm{m}$-microelectrode and the $250 \mathrm{~nm}$-nanocoating. Compared with the solution-based methods in surface engineering of 


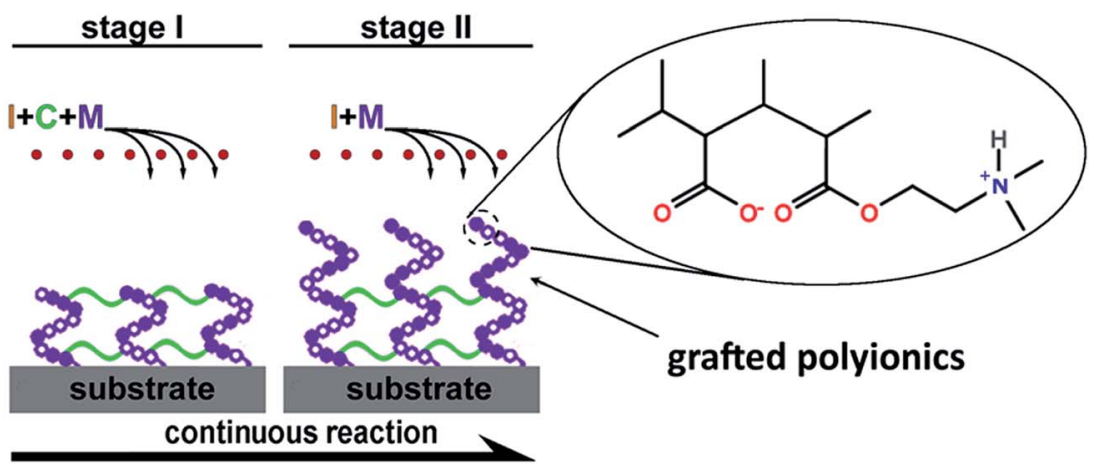

Fig. 1 Schematic illustration for the one-step iCVD synthesis of polyionic PDME. TBP was used as the initiator (I), MAA and DMAEMA were used as the monomers (M), and EGDA was used as the crosslinker (C). PME and PDE were synthesized by a similar procedure, except that only MAA and DMAEMA were used as monomers, respectively.

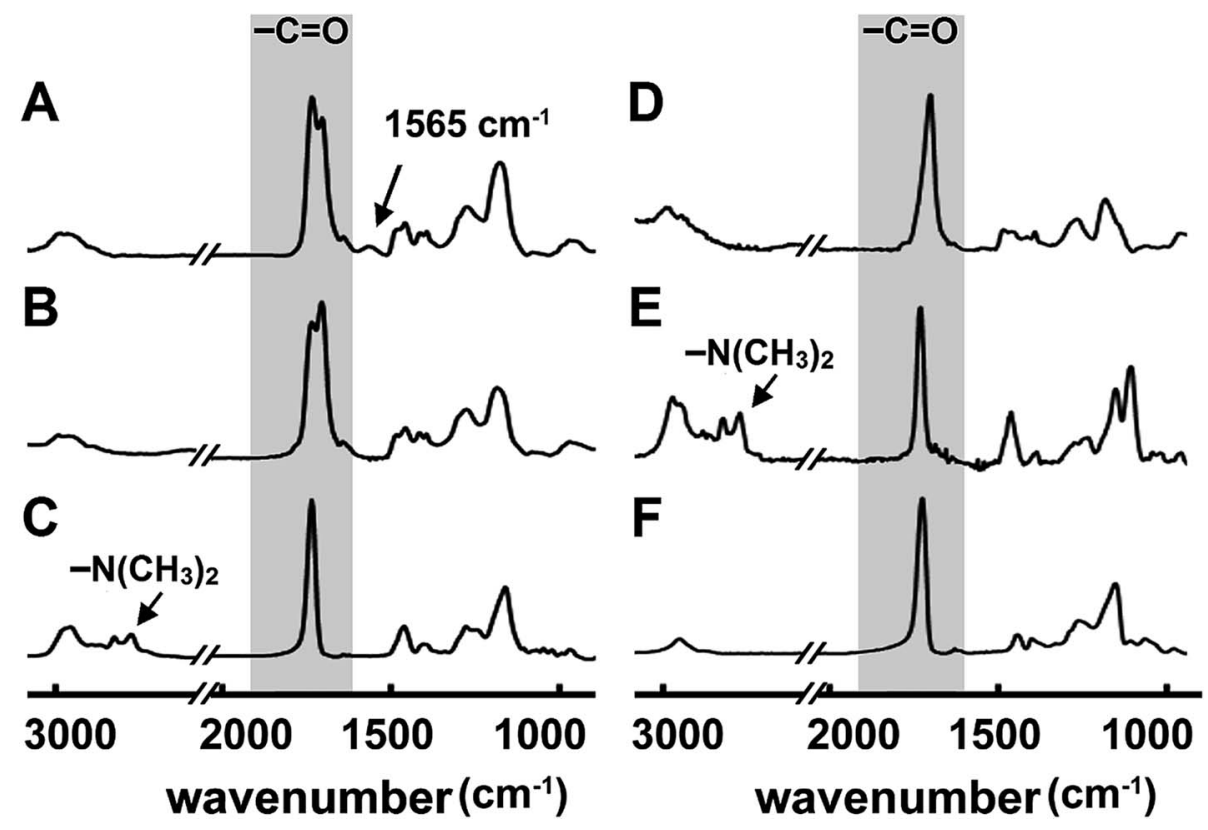

Fig. 2 FTIR spectra of hybrid polyionic nanocoatings of (A) PDME, (B) PME, and (C) PDE, compared with that of homopolymers of (D) PMAA, (E) PDMAEMA, and (F) PEGDA. The absorption peaks at $1702 \mathrm{~cm}^{-1}, 1728 \mathrm{~cm}^{-1}$ and $1735 \mathrm{~cm}^{-1}$ were assigned to $C=O$ stretching of MAA, DMAEMA, and EGDA, respectively. The absorption peaks at 2772 and $2821 \mathrm{~cm}^{-1}$ were assigned to $\mathrm{C}-\mathrm{H}$ stretching of tertiary amine in DMAEMA.

microelectrodes, the vapor deposition method provides the capability to work on electrodes with complex geometry, while maintaining the desired microstructure..$^{52,53}$
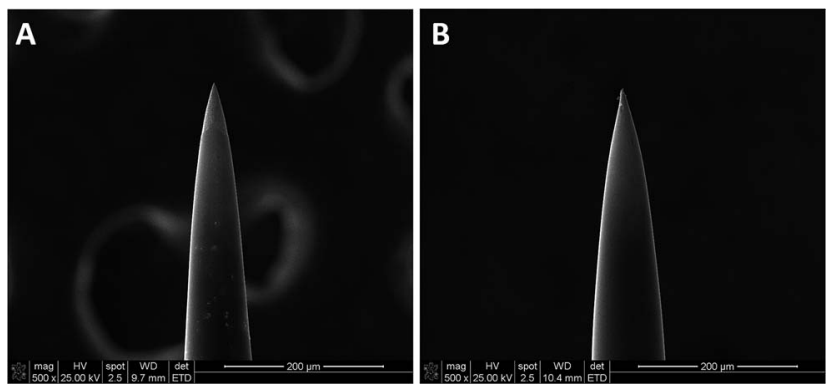

Fig. 3 Neural microelectrodes before (A) and after (B) vapor-deposition of polyionic nanocoating. Scale bar: $200 \mu \mathrm{m}$.

\section{Surface wettability}

The surface wettability of the polyionic nanocoatings was studied by measuring the sessile drop contact angle. The polyionics significantly improved the surface hydrophilicity with much lowered contact angle (Table 2).${ }^{54}$ Similar to that observed on mixed charged zwitterionic coatings, ${ }^{55-57}$ the contact angle of PDME was lower than that of nanocoatings with single charges, possibly due to enhanced solvation of oppositely charged amine and carboxyl moieties. ${ }^{58}$ The contact angle of PME is higher than that of poly(methacrylic acid) brushes, ${ }^{59}$ indicating the presence of the crosslinker component on the hybrid nanocoating surface. The contact angle hysteresis of the hydrogel coatings was in the range of $31.4-39.3^{\circ}\left(34.9^{\circ} \pm 4.0^{\circ}\right)$, possibly due to the configuration change of polymer chains. ${ }^{60}$ The carboxyl and amine moieties were covered by hydrophobic 
Table 2 Measurement of static $\left(\theta_{\mathrm{c}}\right)$, advancing $\left(\theta_{\mathrm{a}}\right)$, and receding contact angle $\left(\theta_{\mathrm{r}}\right)$

\begin{tabular}{llllll}
\hline & $\theta_{\mathrm{c}}\left({ }^{\circ}\right)$ & $\theta_{\mathrm{a}}\left({ }^{\circ}\right)$ & $\theta_{\mathrm{r}}\left(^{\circ}\right)$ & Hysteresis & Mobility factor \\
\hline Control & 83.2 & 88.3 & 66.5 & 21.8 & 0.25 \\
PME & 65.2 & 73.7 & 34.4 & 39.3 & 0.53 \\
PDE & 57.9 & 64.7 & 33.3 & 31.4 & 0.48 \\
PDME & 55.4 & 61.2 & 27.1 & 34.1 & 0.56
\end{tabular}
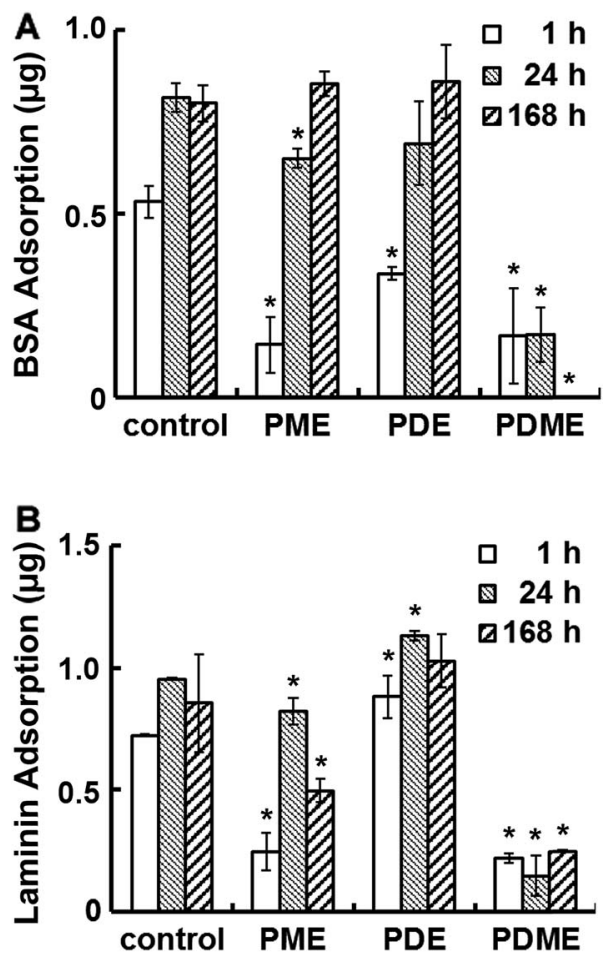

Fig. 4 Protein adsorption on polyionic surfaces. Quantitative amount of BSA (A) and laminin (B) adsorbed per well on negatively charged PME, positively charged PDE, and mixed charged PDME surfaces after $1 \mathrm{~h}, 24 \mathrm{~h}$, and $168 \mathrm{~h}$ of incubation. Significant difference: ${ }^{*} p<0.05$.

moieties of polymer chains to minimize the surface free energy in air. On contacting with water, the carboxyl and amine moieties reoriented and covered the outer surface to minimize free energy in aqueous environment. The mobility factor of the polyionics was around 0.5 , which is much lower than that of the linear zwitterionic polymers. ${ }^{61}$ The lowered mobility again indicated the presence of the crosslinker component on the outer surface, suggesting that the hybrid nanocoating composition can be optimized to further improve surface wettability.

\section{Protein adsorption}

Fig. 4 shows the adhesion of BSA and laminin on PDE, PME, and PDME coated surfaces after incubating for various periods of time. In one hour, the BSA adsorption on PME, PDE and PDME coatings was $0.14 \pm 0.08,0.34 \pm 0.02$, and $0.17 \pm 0.13 \mu \mathrm{g}$ per well, respectively, compared with the control. After $24 \mathrm{~h}$ of incubation, BSA adsorption on PME and PDE increased to $0.65 \pm 0.03$ and $0.69 \pm 0.11 \mu \mathrm{g}$ per well, respectively, while the protein adsorption on PDME remained at $0.17 \pm 0.08 \mu \mathrm{g}$ per well. At $168 \mathrm{~h}$, no detectable BSA adsorption was observed on PDME surface, while PME and PDE surfaces adsorbed 100\% BSA compared with the uncoated surface. The difference in protein adsorption between surfaces with mixed charges and single charges (all positive or all negative) supports the notion that electrical neutrality is important in resisting protein adsorption. ${ }^{55}$ The dynamics of BSA adsorption on PME, PDE, and PDME was studied by monitoring the frequency change using QCM. As shown in Fig. S1, $\uparrow$ the frequency of PDME coated sensor initially decreased and then backed up, and close-to-zero frequency change was recorded at $24 \mathrm{~h}$. In contrast, the frequency of PDE coated sensors showed a trend of continuing declination as time progressed, ending with a frequency reduction of $24.6 \mathrm{~Hz}$ at $24 \mathrm{~h}$. PME coated sensors showed a similar trend of continuing decrease in frequency. According to the Sauerbrey equation, ${ }^{62}$ the frequency reduction is linearly related with the mass of adsorbed protein. The difference in BSA adsorption behavior over time between PME, PDE, and PDME surfaces is consistent with the results observed in the static adsorption test, indicating the potential of using PDME in resisting protein adsorption in the long term.

Compared with the un-coated surface, the adsorption of laminin on PME surface was reduced by $68 \%, 14 \%$, and $50 \%$ in the $1 \mathrm{~h}, 24 \mathrm{~h}$, and $168 \mathrm{~h}$ incubation period, respectively, while PDE surface demonstrated $\sim 20 \%$ increase in laminin
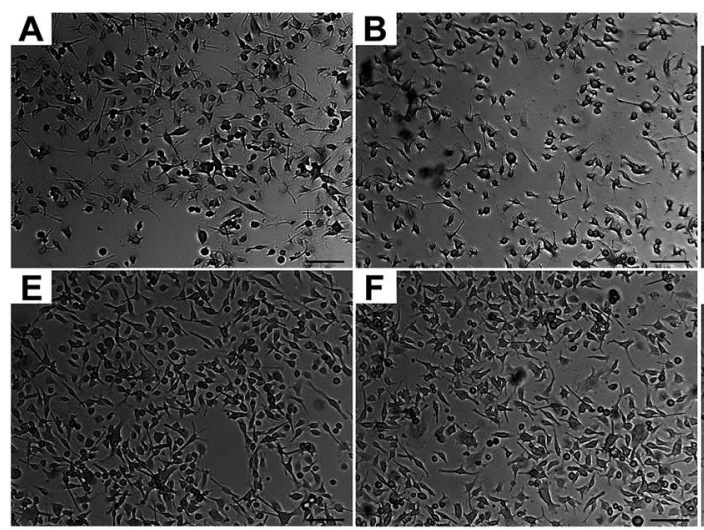
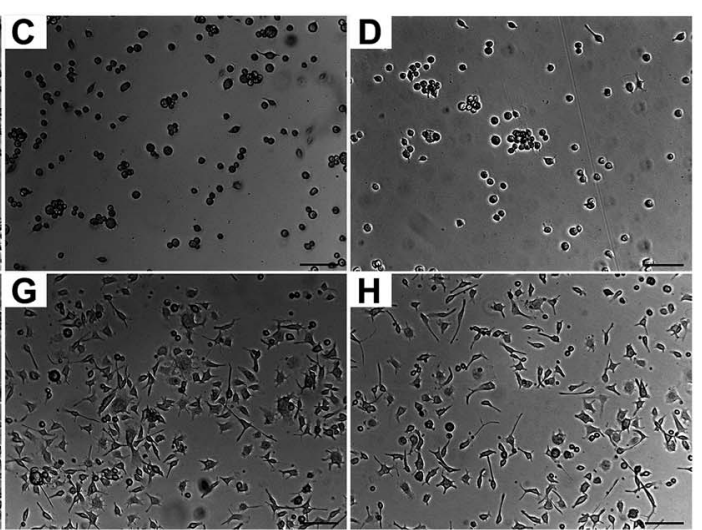

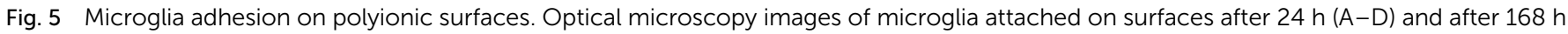
$(E-H)$ : control (A and E), PME (B and F), PDE (C and G) and PDME (D and H). Scale bar is $100 \mu \mathrm{m}$. 

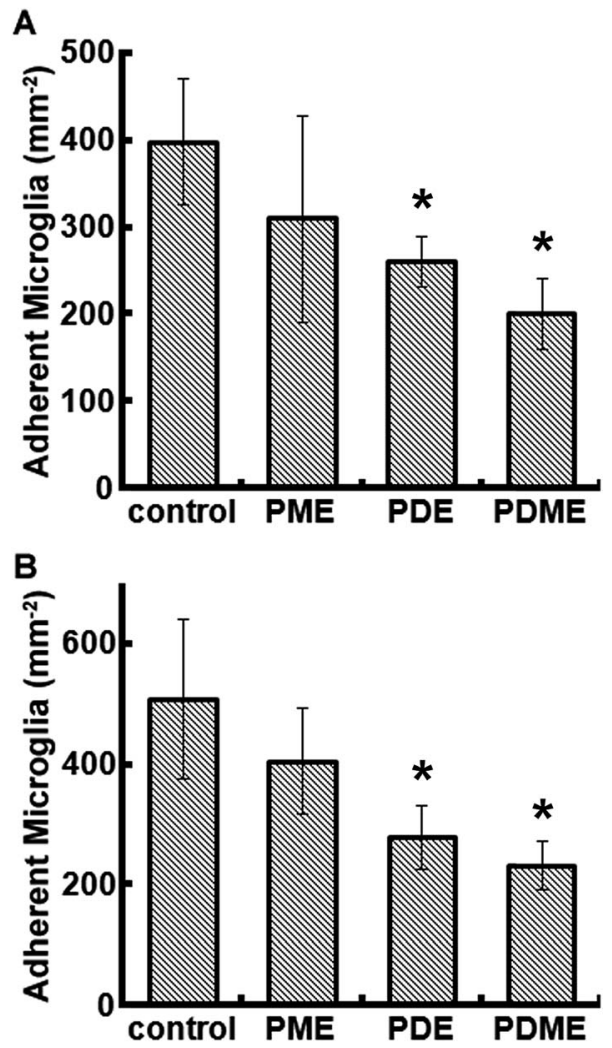

Fig. 6 Quantified microglia adhesion on polyionic surfaces after $24 \mathrm{~h}$ (A) and $168 \mathrm{~h}$ (B) of cell culture. Significant difference: ${ }^{*} p<0.05$.

adsorption regardless of the incubation time. Since laminin has negative charges at neutral $\mathrm{pH},{ }^{63}$ the substantial difference in laminin adsorption between PME and PDE indicated that the surface-protein electrostatic interaction possibly plays an important role in determining laminin adsorption. ${ }^{64}$ The selfassemble nature of laminin $^{65}$ may also contribute to the increase in laminin absorption. In contrast, laminin adsorption on PDME surface was reduced to $0.22 \pm 0.02,0.15 \pm 0.08$, and $0.25 \pm 0.01 \mu \mathrm{g}$ per well within $1 \mathrm{~h}, 24 \mathrm{~h}$, and $168 \mathrm{~h}$, respectively. The reduction of protein adsorption on PDME could be attributed to the surface hydrophilicity in addition to charge neutrality due to the excess energy needed to replace water molecules during protein adhesion. ${ }^{66}$

\section{Microglia adhesion}

Microglia adhesion on the polyionic surfaces was observed using optical microscopy. Representative images are shown in Fig. 5. Morphologically, microglia had amoeboid appearance with pseudopods except on PDE and PDME, where microglia demonstrated a spherical morphology that indicates a lower affinity ${ }^{67}$ at $24 \mathrm{~h}$. The viability of microglia on PDE and PDME was confirmed after transferring and culturing these microglia into regular cell plates, suggesting that the significant reduction in lamellipodia and filopodia was possibly due to the resistance to microglia adhesion and spreading.

The adhesion of microglia decreased on all the surfaces of polyionic nanocoatings (Fig. 6). At $24 \mathrm{~h}$, cell numbers of microglia on PME, PDE, and PDME were reduced by $22 \%, 35 \%$, and $50 \%$, respectively. At $168 \mathrm{~h}$, the microglia adhesion on PME, PDE, and PDME coatings decreased by $20 \%, 45 \%$, and $54 \%$, respectively. The decreased microglia adhesion can be associated with the increasing surface wettability, which leads to lower cell attachment ${ }^{68}$ and reduced cell proliferation rate. ${ }^{69}$ Overall, the surface of PDME was very effective in repelling microglia adhesion in vitro.

\section{Conclusions}

Nanocoatings with polyionics enriched at the surface were synthesized using the iCVD process. Conformal surface engineering of neural microelectrodes was achieved using this single-step, vapor-based method, and the surface ionic composition was facilely tailored. Adhesion of microglia was reduced on all the polyionic modified surfaces, and the polyionics with mixed charges presented the lowest microglial adhesion with more than 50\% reduction in adherent microglia after seven days. In addition, polyionics with mixed charges significantly reduced the surface adsorption of laminin and BSA. The vapor-based nanocoating synthesis bypasses the use of any liquid medium and can be used for the surface engineering of a wide variety of biomedical devices.

\section{Conflicts of interest}

There are no conflicts to declare.

\section{Acknowledgements}

We are grateful for support from CAREER Award of National Science Foundation (CMMI 1056074). We also thank the Oklahoma State University Microscopy Laboratory for the SEM experiments.

\section{References}

1 Z. J. Du, X. L. Luo, C. L. Weaver, et al., J. Mater. Chem. C, 2015, 3, 6515-6524.

2 T. C. Liu, M. C. Chuang, C. Y. Chu, et al., ACS Appl. Mater. Interfaces, 2016, 8, 187-196.

3 G. Deuschl, C. Schade-Brittinger, P. Krack, et al., N. Engl. J. Med., 2006, 355, 896-908.

4 C. de Hemptinne, N. C. Swann, J. L. Ostrem, et al., Nat. Neurosci., 2015, 18, 779-786.

5 M. A. L. Nicolelis, Nat. Rev. Neurosci., 2003, 4, 417-422.

6 A. B. Schwartz, X. T. Cui, D. J. Weber, et al., Neuron, 2006, 52, 205-220.

7 T. Aflalo, S. Kellis, C. Klaes, et al., Science, 2015, 348, 906-910.

8 L. R. Hochberg, M. D. Serruya, G. M. Friehs, et al., Nature, 2006, 442, 164-171.

9 J. P. Seymour and D. R. Kipke, Biomaterials, 2007, 28, 35943607.

10 A. Canales, X. Jia, U. P. Froriep, et al., Nat. Biotechnol., 2015, 33, 277-284. 
11 B. K. Leung, R. Biran, C. J. Underwood, et al., Biomaterials, 2008, 29, 3289-3297.

12 S. Ivens, D. Kaufer, L. P. Flores, et al., Brain, 2007, 130, 535547.

13 S. Franz, S. Rammelt, D. Scharnweber, et al., Biomaterials, 2011, 32, 6692-6709.

14 G. W. Kreutzberg, Trends Neurosci., 1996, 19, 312-318.

15 J. A. Chikar, J. L. Hendricks, S. M. Richardson-Burns, et al., Biomaterials, 2012, 33, 1982-1990.

16 E. Azemi, C. F. Lagenaur and X. T. Cui, Biomaterials, 2011, 32, 681-692.

17 C. L. Kolarcik, D. Bourbeau, E. Azemi, et al., Acta Biomater., 2012, 8, 3561-3575.

18 C. Edward Coffey, W. E. Wilkinson, R. D. Weiner, et al., Biol. Psychiatry, 1993, 33, 442-449.

19 Y. Zhong and R. V. Bellamkonda, J. Controlled Release, 2005, 106, 309-318.

20 Y. Zhong and R. V. Bellamkonda, Brain Res., 2007, 1148, 1527.

21 S. M. Gutowski, J. T. Shoemaker, K. L. Templeman, et al., Biomaterials, 2015, 44, 55-70.

22 E. Schmidt, B. Linz, S. Diekelmann, et al., Brain, Behav., Immun., 2015, 47, 178-185.

23 K. E. Crompton, J. D. Goud, R. V. Bellamkonda, et al., Biomaterials, 2007, 28, 441-449.

24 L. K. Povlich, J. C. Cho, M. K. Leach, et al., Biochim. Biophys. Acta, Gen. Subj., 2013, 1830, 4288-4293.

25 J. D. Nickels and C. E. Schmidt, J. Biomed. Mater. Res., Part A, 2013, 101, 1464-1471.

26 T. D. Y. Kozai, A. S. Jaquins-Gerstl, A. L. Vazquez, et al., Biomaterials, 2016, 87, 157-169.

27 Y. Zhong, X. Yu, R. Gilbert, et al., J. Rehabil. Res. Dev., 2001, 38, 627-632.

28 S. P. Massia, M. M. Holecko and G. R. Ehteshami, J. Biomed. Mater. Res., Part A, 2004, 68, 177-186.

29 Y. Arima and H. Iwata, Biomaterials, 2007, 28, 3074-3082.

30 M. E. Schroeder, K. M. Zurick, D. E. McGrath, et al., Biomacromolecules, 2013, 14, 3112-3122.

31 H. W. Chien, C. C. Tsai, W. B. Tsai, et al., Colloids Surf., B, 2013, 107, 152-159.

32 A. W. Bridges, N. Singh, K. L. Burns, et al., Biomaterials, 2008, 29, 4605-4615.

33 K. B. Bjugstad, K. Lampe, D. S. Kern, et al., J. Biomed. Mater. Res., Part A, 2010, 95, 79-91.

34 Y. Lu, D. F. Wang, T. Li, et al., Biomaterials, 2009, 30, 41434151.

35 D. Kim, J. A. Wiler, D. J. Anderson, et al., Acta Biomater., 2010, 6, 57-62.

36 Y. Y. Duan, G. M. Clark and R. S. C. Cowan, Biomaterials, 2004, 25, 3813-3828.

37 Z. J. Du, X. Luo, C. L. Weaver, et al., J. Mater. Chem. C, 2015, 3, 6515-6524.

38 R. V. Shannon, IEEE Trans. Biomed. Eng., 1992, 39, 424-426.
39 D. R. Merrill, M. Bikson and J. G. R. Jefferys, J. Neurosci. Methods, 2005, 141, 171-198.

40 T. D. Y. Kozai, N. B. Langhals, P. R. Patel, et al., Nat. Mater., 2012, 11, 1065-1073.

41 Y. Ye and Y. Mao, J. Mater. Chem., 2011, 21, 7946-7952.

42 Y. Ye, Q. Song and Y. Mao, J. Mater. Chem., 2011, 21, 1318813194.

43 Y. Ye, Y. Mao, H. Z. Wang, et al., J. Mater. Chem., 2012, 22, 2449-2455.

44 Y. Ye and Y. Mao, RSC Adv., 2017, 7, 24569-24575.

45 R. Milner and I. L. Campbell, J. Neurosci., 2002, 22, 15621572.

46 T. Wang, W. Zhang, Z. Pei, et al., FASEB J., 2006, 20, 906-915.

47 K. Futamura, R. Matsuno, T. Konno, et al., Langmuir, 2008, 24, 10340-10344.

48 L. Wang, W. Wang, L. Di, et al., Colloids Surf., B, 2010, 80, 7278.

49 F. B. De Sousa, J. D. T. Guerreiro, M. Ma, et al., J. Mater. Chem., 2010, 20, 9910-9917.

50 K. Yliniemi, B. P. Wilson, F. Singer, et al., ACS Appl. Mater. Interfaces, 2014, 6, 22393-22399.

51 L. D. Deng, Y. L. Zhai, S. T. Guo, et al., J. Nanopart. Res., 2009, 11, 365-374.

52 Y. Hargsoon, C. D. Devesh, R. Vasuda, et al., Nanotechnology, 2008, 19, 025304.

53 S. Sommakia, H. C. Lee, J. Gaire, et al., Curr. Opin. Solid State Mater. Sci., 2014, 18, 319-328.

54 L. S. Puah, R. Sedev, D. Fornasiero, et al., Langmuir, 2010, 26, 17218-17224.

55 R. E. Holmlin, X. X. Chen, R. G. Chapman, et al., Langmuir, 2001, 17, 2841-2850.

56 L. Mi, M. T. Bernards, G. Cheng, et al., Biomaterials, 2010, 31, 2919-2925.

57 Z. Q. Cao and S. Y. Jiang, Nano Today, 2012, 7, 404-413.

58 R. G. Laughlin, Langmuir, 1991, 7, 842-847.

59 R. Dong, M. Lindau and C. K. Ober, Langmuir, 2009, 25, 4774-4779.

60 J. H. Wang, P. M. Claesson, J. L. Parker, et al., Langmuir, 1994, 10, 3887-3897.

61 Y. Xu, M. Takai and K. Ishihara, Biomaterials, 2009, 30, 49304938.

62 G. Sauerbrey, Z. Phys., 1959, 155, 206-222.

63 H. von der Mark, E. Poschl, H. Lanig, et al., J. Mol. Biol., 2007, 371, 1188-1203.

64 T. Ekblad, O. Andersson, F. I. Tai, et al., Langmuir, 2009, 25, 3755-3762.

65 Y. S. Cheng, M. F. Champliaud, R. E. Burgeson, et al., J. Biol. Chem., 1997, 272, 31525-31532.

66 H. Noh and E. A. Vogler, Biomaterials, 2006, 27, 5801-5812. 67 N. Stence, M. Waite and M. E. Dailey, Glia, 2001, 33, 256-266.

68 X. Dou, D. Zhang and C. Feng, Langmuir, 2013, 29, 1535915366.

69 Y. W. Wang, Q. Wu and G. Q. Chen, Biomaterials, 2003, 24, 4621-4629. 